\title{
Comparison Analysis of Chinese University MOOC(Massive Open Online Course) and K-MOOC(Korea Massive Open Online Course) from the Standpoint of Learners
}

\author{
Lixia Zhai1), Seoyoung Shin2)
}

\begin{abstract}
This study compared the difference between Chinese University MOOC (Massive Open Online Courses) and K-MOOC (Korea Massive Open Online Course) based on the contents and classifications of the courses, the course service structures, and the evaluation methods from the standpoint of learners through literature survey and comparison analysis. The study findings revealed that the Chinese University MOOC provides variety contents to students, schools, and also companies; the classification of K-MOOC courses is done according to level of difficulty and language. Also, both the Chinese MOOC and K-MOOC course service structures platforms have no quizzes and multi-language subtitles within the videos. Furthermore, the study findings revealed that the evaluation methods have no standards and have very different difficulty level to finish a course. Basing on study findings, there is a need for adding various contents to K-MOOC, classifying courses clearly in Chinese University MOOC, adding multi-language subtitles and quizzes in course videos to both platforms.
\end{abstract}

Keywords : MOOC, Chinese, University, K-MOOC, Comparison, Analysis

\section{Introduction}

The rapid development of information and communication technology has a great influence on socio-cultural, lifestyle as well as education. Traditional education is that teachers teach to students in the place which is called school. But now days, the development of sophisticated technology has led everyone learn through different ways such as the MOOC (Massive Open Online Course) any place at any time[1]. MOOC is an open up education platform that enable learners to access the college-level education free of charge[2]. The term MOOC was coined in

Received(April 26, 2019), Review Result(1st: May 20, 2019, 2nd: July 17, 2019), Accepted(September 10, 2019)

1) (Master, The first author) 46241 Department of Education, Pusan National University, Daegu 63 Road 2 (Jangjeon-dong), Gangjeong-gu Busan, Korea

email: dixiao230@naver.com

2) (Doctor, Corresponding Author) 46241 Department of Education, Pusan National University, Daegu 63 Road 2 (Jangjeon-dong), Gangjeong-gu Busan, Korea

email: tjdudssam@naver.com 
Comparison Analysis of Chinese University MOOC(Massive Open Online Course) and K-MOOC(Korea Massive Open Online Course) from the Standpoint of Learners

2008 by Dave Cormier of the University of Prince Edward Island and Bryan Alexander of Research Institute at Athabasca University[3]. Today it has become a hot topic and used in many countries around the world.

Like other countries, in China, MOOC has significant impact and influence on higher education. Since 2012, Chinese universities and some private organizations began to explore and try to use the MOOC model. 2013 which is known as "the year of Chinese MOOC", since this year learning through MOOC became very popular in the country and several MOOC service platforms were established such as 'Shanghai High School Course Center', 'Xuetangx', 'Guokr', 'ewant'[3]. On the other hand, some educational researchers started to conduct more research in the area of MOOC and through the database CNIK (China National Knowledge Infrastructur e) we can know this about 11,158 researches have been done until April 2019. Various topics about MOOC are studied such as how to operate MOOC in universities, also the effect or existing problem during the operating, the interaction between MOOC, Slipped education and SPOC (Small Private Online Course), the analysis of the existing problems and so on[4][5]. About the researches on Korean MOOC, only one scholar introduced basic information about K-MOOC in briefly and have no comparison analysis between the Chinese MOOC services and the Korean MOOC services[6].

In the case of Korea, until April 1, 2019, 1205 researches have been done in the database RISS (Research Information Sharing Service) of Korea. There are several studies about the introduction, current status, and prospect of MOOC[7-9], also many studies have been done about the strategic, existing problems, execution program design, learner motivation and so on [10-12]. Despite the fact that many studies in the areas related to MOOC in Korea, little is known about the comparison analysis of the Chinese MOOC service and the Korean MOOC service. And as results of searching 'MOOC China' in Korea RISS, there are only one study about the trend of Chinese MOOC, one study about the learner satisfaction of Chinese MOOC [13][14].

This lake of information sharing between Korea and China about MOOC calls for making comparison of MOOC services between two countries from the standpoint of the learners. In making comparison will help to identify strengths and weaknesses from each country and find a way forward to improve learning through MOOC in higher learning institutions in China and Korea. In order to make reference from each country, the study employed the following research questions 
Research questions:

1. What are the results of the comparison between Chinese University MOOC and K-MOOC about the contents and classifications of the courses?

2. What are the results of the comparison between Chinese University MOOC and K-MOOC about the course service structures?

3. What are the results of the comparison between Chinese University MOOC and K-MOOC about the evaluation methods?

\section{Theoretical Background}

\subsection{Concept and Global Trend of MOOC}

According to the report of National Lifelong Education Promotion Agency February 2017, MOOC simplify is massive open online course and open online courses which enables learners to have access through the web. MOOC provide convenient environment for learners to learn on their own pace and time. Unlike the existing education system, MOOC eliminate the limitations of time and space, share the educational resources, make the learning process more autonomous, and personalize the learning style. It has gained the reputation as the greatest innovation in education after the invention of the paper making. In 2012, MOOC became a hot topic in education all over the world, and MOOC services such as Udacity, Edx, and Coursera, which have the largest scale and influence until now have been established in USA. Other countries adapted MOOC include the Chinese University of MOOC, xuetangx of China, K-MOOC of Korea, Future learn of England, University of Germany, open2study of Australia and ALISON of Ireland. And now days both China and Korea have considerable interest in the development of MOOC program[15].

\subsection{Chinese University MOOC}

In China the MOOC started as 30 universities in Shanghai cooperating with each other and established the 'Shanghai High School Course Center' in 2013. There are mainly four MOOC services in China with great influence. They are Chinese university MOOC which is established in May 2014, Xuetangx which is established in October 2013, Index which is established in 2014, and Guokr which is established in May 2013. However, Chinese University MOOC has the greatest impact guided by the slogan 'excellent universities have no walls'. Chinese 
Comparison Analysis of Chinese University MOOC(Massive Open Online Course) and K-MOOC(Korea Massive Open Online Course) from the Standpoint of Learners

University MOOC is in charge of the high-quality lecture of the Ministry of National Education whereby 319 prestigious universities are participating. It has been approved by the Ministry of Education and has a positive value of providing high quality lectures in different prestigious universities, provision of educational resources sharing and lifelong education[16].

\section{$2.3 \mathrm{~K}-\mathrm{MOOC}$}

K-MOOC stared in 2015 as the response global trend of MOOC[17]. In 2015 the Korean Ministry of Education, which is in charge of the K-MOOC, set up concrete proposal to guide the program. Since K-MOOC is a state-led higher education platform, the general goals of the program are balancing of higher education opportunities, the laying of the foundation for lifelong learning and the development of promoting national human[18]. The K-MOOC is classified into three categories according to the duration of study: short-term (1 to 6 weeks), intermediate (7 to 12 weeks), and long-term courses (13 weeks or more). Each lecture is about 15 minutes, and it has various learning activities such as questions and answers, discussion, quizzes, and assignments.

\section{Research Method}

The study, summarized the research literatures from 2014 with the keyword in the papers database of China and Korea. As search engines, Chinese representative academic database CINK (China National Knowledge Infrastructure) and Korean representative academic database RISS (Research Information Sharing Service) were used. Through literature survey we were able to establish background, current status, existing research topics of MOOC. For the research question one (1), we searched web pages of Chinese University MOOC and K-MOOC to the contents and classifications of all the courses (Table 1, Table 2). For the research question two (2) and three (3), researchers ordered 200 courses of Chinese University MOOC and 200 courses of K-MOOC to understand course service structures such as whether there is subtitle, introduction video, etc. (Table 3). Also, used analyze the evaluation methods the learners.

\section{Research Result}

\subsection{The Comparison of the Contents and Classification of Courses}

At the homepage of Chinese University MOOC is hard to confirm the information of the 
courses only by clicking the lower classes in the major category. There is the main category at the left side of the homepage and the number of courses of each category is not visible. Learners only can get the detailed information at the second category. On the other hand, K-MOOC homepage at the right side, it is easy to check the information of the courses through the clearly classification about the learning period, language, difficulty level, etc. But at the Chinese University MOOC, there are more various contents and functions which can improve the value of MOOC.

The classification of the courses on both platforms is as below.

[Table 1] Chinese University MOOC Courses Classification

\begin{tabular}{|c|c|c|c|}
\hline No. & Main category & Quantity & Proportion(\%) \\
\hline 1 & Engineering & 661 & 22.33 \\
\hline 2 & Science & 448 & 15.14 \\
\hline 3 & Computer & 289 & 9.76 \\
\hline 4 & Medicine & 267 & 9.02 \\
\hline 5 & Management & 256 & 8.65 \\
\hline 6 & Education & 192 & 6.49 \\
\hline 7 & Literature & 157 & 5.30 \\
\hline 8 & Art and Physical & 138 & 4.66 \\
\hline 9 & Foreign Language & 139 & 4.70 \\
\hline 10 & Law & 126 & 4.26 \\
\hline 11 & Economics & 115 & 3.89 \\
\hline 12 & Psychology & 35 & 1.18 \\
\hline 13 & Agriculture & 55 & 1.86 \\
\hline 14 & Philosophy & 36 & 1.22 \\
\hline 15 & History & 46 & 1.55 \\
\hline
\end{tabular}

[Table 2] K-MOOC Courses Classification

\begin{tabular}{|c|c|c|c|}
\hline No. & Main Category & Quality & Proportion(\%) \\
\hline 1 & Humanities & 204 & 26.56 \\
\hline 2 & Social & 185 & 24.09 \\
\hline 3 & Engineering & 163 & 21.22 \\
\hline 4 & Nature & 89 & 11.59 \\
\hline 5 & Art and Physical Education & 52 & 6.77 \\
\hline 6 & Medicine & 45 & 5.86 \\
\hline 7 & Education & 30 & 3.91 \\
\hline
\end{tabular}

In the case of main categories, it is easy to see that Chinese university MOOC is more subdivided and K-MOOC is more briefly separated. It is easily to see that the proportion of science and technology courses such as engineering, science, and computer is higher of Chinese university MOOC, on the other hand, it is easy to see the proportion of humanities and social 
Comparison Analysis of Chinese University MOOC(Massive Open Online Course) and K-MOOC(Korea Massive Open Online Course) from the Standpoint of Learners

studies courses is higher of K-MOOC. The proportion of arts and physical education is $4.66 \%$ for Chinese university MOOC and $6.77 \%$ for K-MOOC. The proportion of courses related to education is $3.91 \%$ for K-MOOC and $6.49 \%$ for Chinese University MOOC. Making reference to the sub-categories of K-MOOC, it is easy to understand number of the courses related to language and literature about 77 and the proportion is about $10.02 \%$, almost equal to the proportion of this field of Chinese University MOOC's 10\%.

\subsection{The Comparison of Course Service Structures}

The course service structure provided in the process of completing a specific course by the teachers and MOOC service organizations need to ensure that the necessary services are provided. So that teachers can teach well, learners can study convenient and effective, also all the participants can communicate fluently. In [Table 3] we can see that the Chinese university MOOC and K-MOOC operate in a similar way about the course service structures, but there are little differences can be seen.

[Table 3] The Compare Between Chinese University MOOC Service and K-MOOC Service

\begin{tabular}{|c|c|c|c|}
\hline & Course Service Structure & $\begin{array}{c}\text { Chinese University } \\
\text { MOOC }\end{array}$ & K-MOOC \\
\hline \multirow{7}{*}{ Course Outline } & Course Plan & $\sqrt{ }$ & $\sqrt{ }$ \\
\hline & Course Summary & $\sqrt{ }$ & $\sqrt{ }$ \\
\hline & Guide Video & $\sqrt{ }$ & $\sqrt{ }$ \\
\hline & Number of Learners & $\sqrt{ }$ & $\sqrt{ }$ \\
\hline & Notification of Course Progress & $\sqrt{ }$ & $\sqrt{ }$ \\
\hline & Evaluation Method & $\sqrt{ }$ & $\sqrt{ }$ \\
\hline & Credit of Agreement & $\sqrt{ }$ & $\sqrt{ }$ \\
\hline \multirow{5}{*}{ Courses Video } & Quiz in Video & $x$ & $x$ \\
\hline & Course Video Download & $\sqrt{ }$ & $\sqrt{ }$ \\
\hline & Subtitles Download & $x$ & $\sqrt{ }$ \\
\hline & Speed Adjustable & $\sqrt{ }$ & $\sqrt{ }$ \\
\hline & Multi-language Subtitle & $x$ & $x$ \\
\hline \multirow{4}{*}{$\begin{array}{c}\text { Homework and } \\
\text { Test }\end{array}$} & Test After Video & $\sqrt{ }$ & $\sqrt{ }$ \\
\hline & Comment & $\sqrt{ }$ & $\sqrt{ }$ \\
\hline & Classification of Comment & $\sqrt{ }$ & $\sqrt{ }$ \\
\hline & Debate Space & $\sqrt{ }$ & $\sqrt{ }$ \\
\hline \multirow{2}{*}{ Course Materials } & Slide Download & $\sqrt{ }$ & $\sqrt{ }$ \\
\hline & References Materials & $\sqrt{ }$ & $\sqrt{ }$ \\
\hline Assistant & With or Without & $\sqrt{ }$ & $\sqrt{ }$ \\
\hline
\end{tabular}

By observing [Table 3], it can be deduced that services of course overview are equipped well 
both Chinese University MOOC and K-MOOC. Chinese University MOOC connect with students not only by email but also through the communication app Wechat (Chinese SNS Service) which simplify notifications effectiveness because it is used by majority of Chinese people. In the selection of the course video, both platforms appear to have no quizzes within the video and no multi-language subtitles. In the case of Chinese University MOOC only some courses about foreign languages education have English subtitles. While, in the case of K-MOOC, has no multi-language subtitles but English subtitles are available, and able to download.

\subsection{The Comparison of Evaluation Methods}

MOOC removes the barriers of higher education and provides equal opportunity to all the people to receive higher education easily. However, the problem remains is low completion rate for any country. Most MOOC courses have a graduation proportion of about 10\%[19]. Appropriate evaluation methods can determine the value of a course and serve as promotion and encouragement for student's learning. In order to check the standards of the evaluation methods researchers ordered 200 courses in the Chinese University MOOC and 200 courses in the K-MOOC.

In Chinese University MOOC, the referred evaluation methods include test score, discussion, homework activities, mid-term examination and final examinations. Students get the certificate of completion once they reach the specified score. Test score is through the quizzes which is appeared after the course video and evaluation is done automatic online. Discussions are assessed by teachers through students' posting comments and the participation performance in the Wechat(Chinese SNS Service) chatting group. Homework assessments are finished by teachers or the students who already submitted their homework. Some teachers specify details such as the number of comments and the times of mutual evaluations, even the content of the comments. But other teacher only set the midterms and final exams. Students can receive a certificate of the achievement if their final score is 80 and above, but some just need 60 and above. Also, time for uploading students' examinations answers is different, some is only 1 time, but some is 2 or 3 times. This pose serious difference in the difficulty level to finish a course.

In K-MOOC, the final grades are included attendance, quizzes, midterm, final exam, discussion. Also, there is a big difference about which selections to choose, and the proportion of each selection. Mostly if students can get more than 60 points as the final grades, they can 
Comparison Analysis of Chinese University MOOC(Massive Open Online Course) and K-MOOC(Korea Massive Open Online Course) from the Standpoint of Learners

get the certificate of the achievement.

It is clear that both Chinese University MOOC and K-MOOC are crowded and have no standard about the evaluation method. Although it is normal that the evaluation content and method are not the same because the nature of a courses, but to ensure the quality and the social recognition of the certificate it is necessary to establish an evaluating system with similar difficulty level.

\section{Conclusion}

This study compared the difference between Chinese University MOOC and K-MOOC on the contents and classification of the courses, the course service structures, also the evaluation methods from the standpoint of learners. The following suggestions are based on the research results of this study.

First, at the homepage of K-MOOC is well structured and easy to check information of the courses through the classifications based on learning period, language and difficulty level. Chinese University MOOC have something to adapt from K-MOOC through providing details at the homepage to help users access information more easily and get detailed information.

Second, this study provided two key suggestions on course services and structures for both Chinese university Mooc and K-mooc as follows: In order to have broader range of access and simplicity to learners from different backgrounds multi-language is better to be customized in their systems. And quizzes to be included to improve the learning as means of reflections. Udacity and coursera can be used as example by providing references.

Third, it's about the evaluation methods. Both Chinese University MOOC and K-MOOC ways of evaluating are different. There is a big difference in the degree of difficulty. Therefore, to ensure the quality and the social recognition of the certificate it is also necessary to establish an evaluating system with similar difficulty level.

\section{References}

[1] Young Joo Ju, Dong-shim Kim, A Study of Satisfaction and Intention to Use MOOC Based on UTAUT2 in Korea, Journal of Lifelong Learning Society, (2017), Vol.13 No.1, p.185-207, UCI: G704-SER000015054.2017.13.1.004

[2] Aaron Bady, The MOOC Moment and the End of Reform, Liberal Education, (2013), Vol.99, p.118-119. 
[3] Sizhi Li, Shaofei Wang, Yanhong Li, Analysis of MOOC's Development Causes and Trends in China, 4th International Conference on Applied Social Science, (2014), March 20; Singapore

[4] Zhu Haibin, A study on the strategy of introducing MOOC in full-time graduate degree teaching, Bohai University, Master's Thesis, (2017)

[5] Yuxia Sang, Research on college students' learning experience and outcome of SPOC-based Flipped Classroom-A case study on the course circuiit analysis, Nanjing University, Master's Thesis, (2012)

[6] Wu Jianjin, 2018 Korea's large-scale open curriculum construction plan released, Journal of World Education, (2018), No.8, pp.78-79.

[7] Cho Il-hyun, Combining Flipping MOOC and Learning Analytics: Extension of the LAPA Model for the Free-mium Economy Era, The Korean Society for Educational Technology, (2015), Vol.2015, No.1, p.57.

[8] Kyungae Choi, Tasks for Effective Use of K-MOOC as a Higher Continuing Education, Journal of Lifelong Learning Society, (2016), Vol.12, No.2, p.1-24, UCI: G704-SER000015054.2016.12.2.004

[9] Changun Park, An Analysis of Problems and Subject Matter in the Operation of K-MOOC, The Journal of Curriculum Studies, (2016), Vol.34, No.2, pp.121-140, UCI: G704-000671.2016.34.2.007

[10] KyungHee Song, MOOC Curation Design for Non-native English Speaking Learners: Focused on an Implementation Case of Business English Course for Global Projects, Korea Broadcasting and Telecommunications University, Master's Thesis, (2014)

[11] Munheum Jo, Mungyeong Byeon, College Students' Motivation and Learning Patterns in Massive Open Online Courses (MOOCs), Korean Journal of Educational Research, (2016), Vol.53, No.4, pp.193-223, UCI: G704-000614.2015.53.4.001

[12] Jin-Il Kim, The Finding Core Functions for Standardization of Korea MOOCs Platform, Journal of Korean Institute of Information Technology, (2016), Vol.14, No.3, pp.137-145, DOI: 10.14801/jkiit.2016.14.3.137

[13] Gwang Ossang, Research Trend Analysis on Chinese MOOC for higher education from 2012 to 2016, Busan University, Master's Thesis, (2017)

[14] Wu Qi, A Study on Learner Satisfaction Learning Outcomes and Reuse Intention in e-Learning: Centering on China MOOC platforms, Busan University, Master's Thesis, (2018)

[15] Wang Weifang, Fan Weibin, Path Choice of Higher Vocational Teaching Model Reform in MOOCS Times, Journal of Tianjin Vocational University, (2014), Vol.23, No.2, pp.7-10.

[16] https://baike.so.com/doc/27384049-28790018.html, Apr 2 (2019)

[17] Changun Park, Possibilities and Limitations of the K-MOOC for the Open Curriculum Training, The Journal of Yeolin Education, (2016), Vol.24, No.4, pp.67-83, DOI: 10.18230/tjye.2016.24.4.67

[18] Ju-kyung Kim, An analysis of K-MOOC structural relationship among characteristics and educational effectiveness, Korea University, Doctoral Thesis, (2018)

[19] Liu Na, The research and practice of MOOC quality evaluation method based on learner perspective, Beijing University of Posts and Telecommunications, Doctoral Thesis, (2016) 